\title{
Sigmoid Flexure
}

National Cancer Institute

\section{Source}

National Cancer Institute. Sigmoid Flexure. NCI Thesaurus. Code C33550.

The curving part of the colon that is in continuity with the rectum. 